\title{
Immune Response Process
}

National Cancer Institute

\section{Source}

National Cancer Institute. Immune Response Process. NCI Thesaurus. Code C17930.

Any immune system response of an organisms to an internal or invasive threat. 